\title{
Tissue-specific response of primary metabolites in tomato plants affected by different $\mathrm{K}$ nutrition status
}

\author{
Jwakyung Sung ${ }^{1}$, Hejin Yun ${ }^{1}$, Minji Cho ${ }^{1}$, Jungeun Lim $^{1}$, Seulbi Lee ${ }^{1}$, Deogbae Lee ${ }^{1}$, Taek-Keun Oh$^{2, * *}$ \\ ${ }^{1}$ Soil and Fertilizer Division, NIAS, RDA, Wanju, Jeollabuk-do, 55365, Korea \\ ${ }^{2}$ Department of Bio-Environmental Chemistry, Chungnam National University, 99 Daehak-Ro, Yuseong-Gu, \\ Daejeon 34134, Republic of Korea
}

"Corresponding author: ok5382@cnu.ac.kr

\begin{abstract}
As one of the most important mineral nutrient elements, potassium $(\mathrm{K})$ plays crucial roles in many fundamental processes, including enzyme activation, membrane transport, anion neutralization and osmo-regulation, and determines the yield and quality of crop production. In order to better understand and elucidate plant tissue-specific primary metabolic changes under different $\mathrm{K}$ nutrition status. Four-week-old tomato plants were subjected to different $\mathrm{K}$ nutrition situations: low $(0.25 \mathrm{mM})$; normal $(2.5 \mathrm{mM})$; and high $(10.0 \mathrm{mM})$; and the emerging leaves, fully expanded leaves, petioles, stem and roots were harvested at 15 and 30 days, time points which the external symptoms are observed, after K treatments. Primary metabolites, amino acids, organic acids and sugars, extracted from each tomato tissue were measured with HPLC system. Several interesting findings from this study could be summarized as follows: (1) metabolites showed K-dependent responses, which indicated that the rates of an increase and decrease in low K-affected were $50 \%: 50 \%$; whereas, $80 \%: 20 \%$ in high $\mathrm{K}$; (2) the petioles revealed the most sensitive plant tissue in response to $\mathrm{K}$ nutrition status; and (3) metabolites such as glucose and fructose (soluble sugars), malate and citrate (organic acids), and glutamine, asparagine, glutamate and aspartate (amino acids) strongly fluctuated (up or down) by the K nutrition ratio. These findings may contribute to a better understanding and elucidating the tissue-specific biosynthetic patterns and primary metabolite accumulation under different $\mathrm{K}$ nutrition ratios, and provide a new strategy for comprehensive information involved in the spatio-temporal metabolic networks
\end{abstract}

Keywords: Tomato; low potassium; high potassium; primary metabolites.

Abbreviations: K_Potassium; DAT_Days after treatment; OPA_o-phthalaldehyde; FMOC_Fluorenylmethyl chloroformate; LSD_Least significant difference

\section{Introduction}

Although the fact that potassium $(\mathrm{K})$ is not assimilated into organic compounds unlike nitrogen, phosphorus, and sulfur, it is evident that $\mathrm{K}$ is a significant facilitator in metabolism such as direct enzyme activation (Wyn Jones and Pollard, 1983), long distance transport of solutes and osmotic regulation, and the transformer for ribosomal function (Marschner, 1995). Molecular study in plant $\mathrm{K}$ nutrition has focused on the characterization of $\mathrm{K}$ transporters and has provided detailed information on the structure, function, and regulation (Véry and Sentenac, 2003; Amtmann and Blatt, 2009). In contrast, biochemical and molecular evidence of the interaction between $\mathrm{K}$ and metabolites is not defined well. Current knowledge has provided K-dependent primary metabolism showing a strong increase in soluble sugars, accumulation of several basic or neutral amino acids, and a slight increase in total amino acid and protein content whilst being severely depleted in acidic amino acids and organic acids (Amtmann et al. 2008; Armengaud et al. 2009; Sung et al. 2015).

The production of vegetable crops has shown significant yield increases in South Korea over the last several decades. A high level of $\mathrm{K}$ is required to achieve maximized for crop production in vinyl greenhouses. This method of growing maintains crop quality and extends crop harvest periods in South Korea. However, as a result of those described above, most farmers routinely apply $\mathrm{K}$ fertilizer even in a fertilized field, which can result in unfavorable crop growth because of metabolic disturbance.

Although many studies have concentrated on the specific tissues such as leaves, roots, and fruits have found metabolic changes under a variety of adverse mineral environments, more information is required to expand our understanding about minerals-dependent metabolism such as plant tissue-specific metabolite distribution (Hirai et al. 2004; Nikiforava et al. 2004 Bölling and Fiehn, 2005; Urbanczyk-Wochniak and Fernie, 2005; Hernandez et al. 2007; Armengaud et al. 2009; Sung et al 2015).

In this paper we measured primary metabolites, comprised of soluble sugars, organic acids and amino acids, in order to investigate tissue-specific changes in tomato plants primary metabolic changes grown under low- $(0.25 \mathrm{mM})$, normal- $(2.5$ $\mathrm{mM})$ and high- $(10.0 \mathrm{mM}) \mathrm{K}$ nutrition conditions. The focus of this study was on how primary metabolites respond to different $\mathrm{K}$ nutrition levels, and what metabolites and tissue are most sensitive. Several interesting results were uncovered, which 
expands the knowledge on mineral-metabolites interaction and provides strong motivation for future studies in mineral metabolism.

\section{Results}

\section{Tomato growth and water soluble $K$ distribution}

Tomato growth was highly coordinated with soluble $\mathrm{K}$ concentrations of fully expanded leaves $\left(\mathrm{r}=0.89^{* * *}\right.$ ) (Fig. 1). The water-extracted $\mathrm{K}$ concentration showed plant tissue- and $\mathrm{K}$ nutrition-dependent responses at both time points (Fig. 2). The highest $\mathrm{K}$ concentration was found in petioles and followed by leaves, stem and roots, and it was also observed that $\mathrm{K}$ moved into emerging leaves under low $\mathrm{K}$ nutrition. Soluble $\mathrm{K}$ under high $\mathrm{K}$ nutrition led to it being equally distributed throughout all plant tissues.

\section{Time- and tissue-dependent changes of metabolites to} different K nutrition

There was a substantial effect of different $\mathrm{K}$ nutrition on the levels of many primary metabolites in both time point and tissue. Soluble sugars, glucose, fructose and sucrose, responded oppositely with $\mathrm{K}$ nutrition in all tomato tissues (Fig. 3), moreover, their partitioning differed from a type of soluble sugars. Based on the results measured at 30 days after $\mathrm{K}$ treatment (DAT), glucose was predominantly accumulated in the petioles and the stem, fructose in emerging leaves and fully expanded leaves, and sucrose in the stem and roots under all $\mathrm{K}$ nutrition. Relative to the control (normal K), for the most part, absolute concentration in citrate and malate showed significant decrease in both low- and high K(Fig. 4). The majority of the amino acids in all tomato tissues showed a tendency to progressively decrease with increasing levels of $\mathrm{K}$ nutrition except for the emerging and fully expanded leaves at 15 DAT (Table 1). Glutamate was found the most abundant amino acid in emerging and fully expanded leaves, whereas, in petioles, stems, and roots, glutamine was most prevalent. Relative portion (\%) of amino acids was also assessed by C-skeleton backbones such as oxaloacetate, $\alpha$-ketoglutarate, phosphoenolpyruvate, pyruvate and 3-phophoglycerate (Table 2 ). The most dominant amino acid group was $\alpha$-ketoglutarate, which occupied more than $60 \%$, of all tomato tissues. Low K led to a substantial increase in oxaloacetate- and phosphoenolpyruvate-derivatives in emerging leaves and pyruvate- and 3-phophoglycerate-derivates in fully expanded leaves; however, $\alpha$-ketoglutarate-derivates noticeably declined in fully expanded leaves. High $\mathrm{K}$ resulted in a marked increase in $\alpha$-ketoglutarate-derivates in fully expanded leaves, pyruvatederivatives in roots and 3-phophoglycerate-derivatives in petioles. Based on base-2 logarithms calculation, metabolite changes in all tomato tissues, which is clearly illustrated in Fig. 5 , where biosynthetic pathways have been annotated with red (upward) or blue (downward) colors to indicate the response to $\mathrm{K}$ nutrition situation. The metabolite profiles exhibited a profound effect of $\mathrm{K}$ nutrition conditons on the levels of many primary metabolites. Low $\mathrm{K}$ was marked by an increase in the levels of most amino acids, especially Asn, Gln, His and Trp, and a decrease in the levels of organic acids (malate, citrate) and amino acids (Asp, Glu, Arg, Ala, Pro). On the contrary, high $\mathrm{K}$ induced substantial declines in almost all metabolites measured. The analysis of variance (ANOVA, F-test) using SAS program (ver. 9.1) was performed for selected primary metabolites (Table 3). More than $90 \%$ of analyzed metabolites revealed statistically significant differences between time, tissue, and $\mathrm{K}$ nutrition, which means that the biosynthesis, degradation, and accumulation of metabolites was sensitive to internal and external growth environments.

\section{Discussion}

Potassium $(\mathrm{K})$ as the most abundant cation is characterized by high mobility in plants at all levels and in long-distance transport via the xylem and phloem. In this study we measured the concentrations of water soluble $\mathrm{K}$ and primary metabolites from emerging leaves, fully expanded leaves, petioles, stem and roots of tomato plants affected by different $\mathrm{K}$ nutrition conditions. A tendency of $\mathrm{K}$ partitioning was highly sensitive to the levels of K supply. The water-extracted K rapidly moved into emerging leaves (vigorous growing organ) under low $\mathrm{K}$, whereas, in roots it remained low. On the contrary, it was distributed throughout the whole plant tissues, especially petioles, under high K. Growth of many plants on limited K supply has previously been demonstrated to lead to large changes, increase or decrease, in primary metabolites; e.g. strong increase in soluble sugars in leaves of Arabidops (Armengaud et al. 2009), bean (Cakmak et al. 1994a, 1994b), cotton (Bednarz and Oosterhuis, 1999; Pettigrew, 1999), gentian (Takahashi et al. 2012), soybean (Huber, 1984) and wheat (Ward, 1960), alfalfa (Li et al. 1997), sugar beet (Farley and Draycott, 1975), and tomato (Urbanczyk-Wochniak and Fernie, 2005; Sung et al., 2015). However, the information reported from previous studies was mostly focused on the specific tissues such as leaves and roots and mineral deficient conditions. The authors interested in investigating what primary metabolites and tissues are sensitive to different $\mathrm{K}$ nutrition. To achieve this goal, tomato plants were subjected to three $K$ nutrition conditions as described in Materials and Method, and thus the results are mostly descriptive to metabolic events caused by different $\mathrm{K}$ nutrition. It was observed that water soluble $\mathrm{K}$ strongly affected the levels of primary metabolites (Fig. 3 and 4, Table 1). The low $\mathrm{K}$ condition led to the accumulation of carbohydrates in leaves as a replacement of osmotic molecule, and in leaves and roots, in order to drive long-distance transport for K (Cakmak et al. 1994a, 1994b); however, in this study, the levels of soluble sugars (glucose, fructose and sucrose) under low $\mathrm{K}$ remained unchanged or displayed a slight increase in shoots, or strongly increased in the root in accordance with the previous results, which suggests this consequence is due to the restricted sugar usage in the roots and an inhibited activity of $\mathrm{K}^{+}$carriers and channels located at the plasma membrane of root cells (Armengaud et al. 2009; Wang and $\mathrm{Wu}, 2010$ ). As previously reported (Armengaud et al. 2009; Takahashi et al. 2012; Sung et al. 2015), a strong decrease of organic acids (citrate and malate) was also observed in most plant tissues. The total amino acid concentration was the highest in the stem, followed by the petioles, roots and leaves; however, in low K-induced state, a relative increase was found in the petioles (Fig. 5). The most marked changes were a substantial increase in glutamine, asparagine, and histidine in most plant tissues, whereas, the levels of glutamate, aspartate, and proline decreased sharply. Armengaud et al. (2009) reported that several basic or neutral amino acids accumulated during a low $\mathrm{K}$ condition, while acidic amino acids (glutamate, aspartate) decreased. The most likely explanation described above was that low $\mathrm{K}$ in cellular level decreased selectively the concentration in acidic amino acids as well as organic acids in order to contribute to maintaining charge balance, and this interpretation is partially 
Table 1. Temporal and tissues-dependent composition of amino acids in tomato plants at 15 and 30 days after $\mathrm{K}$ treatment $(\mathrm{n}=5)$.

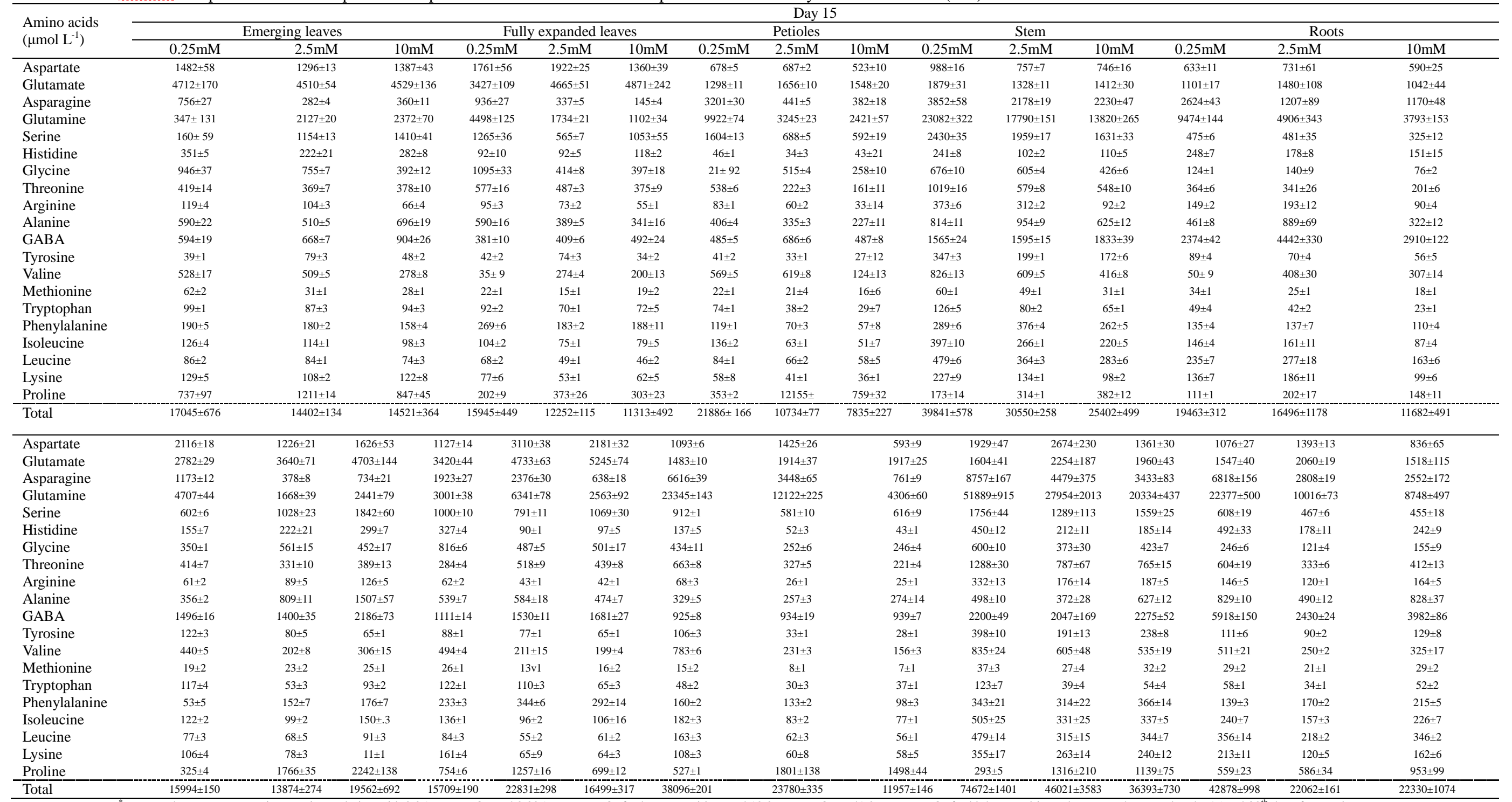

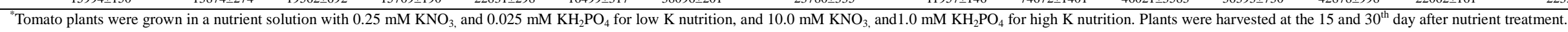


Table 2. Relative portion (\%) of amino acids (carbon skeleton backbones-based) by tissues of tomato plants at 30 days after K treatment.

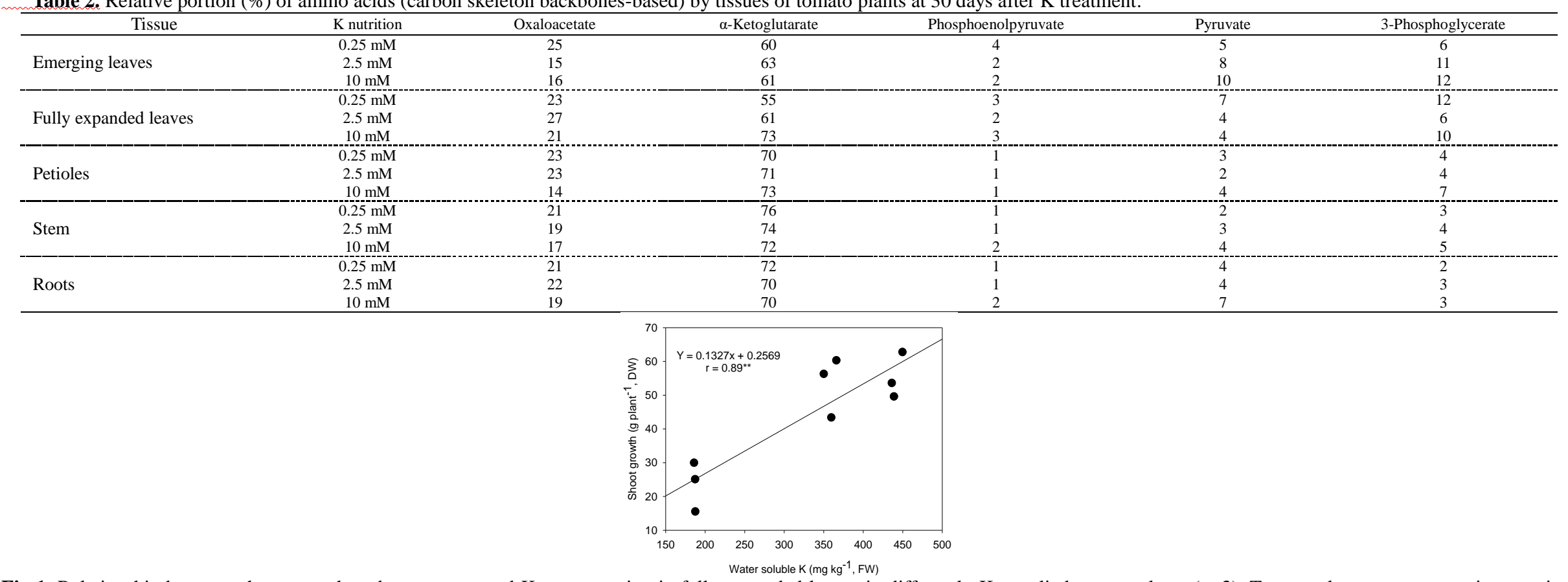

Fig 1. Relationship between shoot growth and water-extracted $\mathrm{K}$ concentration in fully expanded leaves in differently $\mathrm{K}$-supplied tomato plants ( $\mathrm{n}=3$ ). Tomato plants were grown in a nutrient solution with $0.25 \mathrm{mM} \mathrm{KNO}_{3}$, and $0.025 \mathrm{mM} \mathrm{KH}_{2} \mathrm{PO}_{4}$ for low $\mathrm{K}$ nutrition, and $10.0 \mathrm{mM} \mathrm{KNO}$, and $1.0 \mathrm{mM} \mathrm{KH}_{2} \mathrm{PO}_{4}$ for high $\mathrm{K}_{\text {nutrition. }} \mathrm{Plants}$ were harvested at the 15 and $30^{\text {th }}$ day after nutrient treatment.

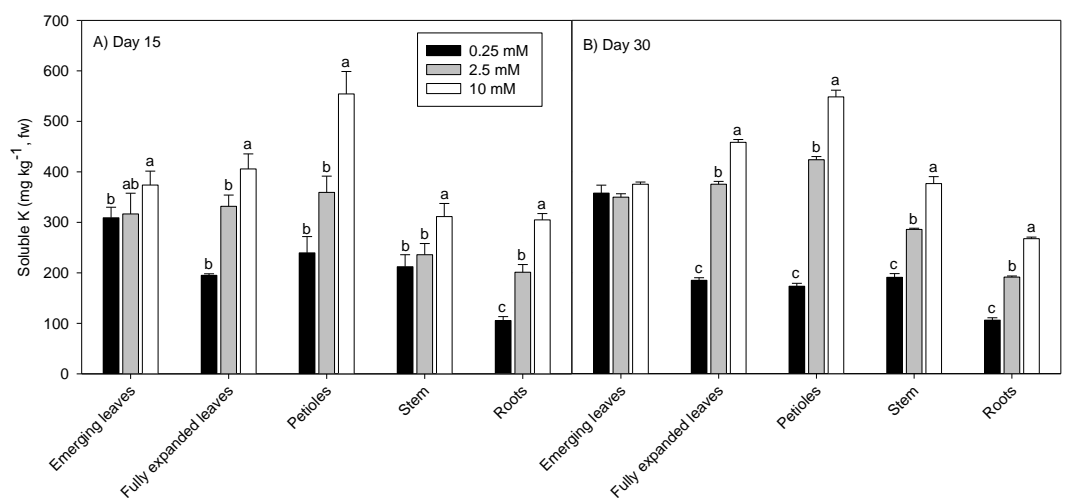

Fig 2. Temporal and tissues-dependent concentrations of water-extracted $\mathrm{K}$ in differently $\mathrm{K}$-supplied tomato plants ( $\mathrm{n}=3$ ). Tomato plants were grown in a nutrient solution with $0.25 \mathrm{mM} \mathrm{KNO}_{3}$, and $0.025 \mathrm{mM} \mathrm{KH}_{2} \mathrm{PO}_{4}$ for low $\mathrm{K}$ nutrition, and $10.0 \mathrm{mM} \mathrm{KNO}_{3}$ and $1.0 \mathrm{mM} \mathrm{KH}_{2} \mathrm{PO}_{4}$ for high $\mathrm{K}$ nutrition. Plants were harvested at the 15 and 30 day after nutrient treatment. 


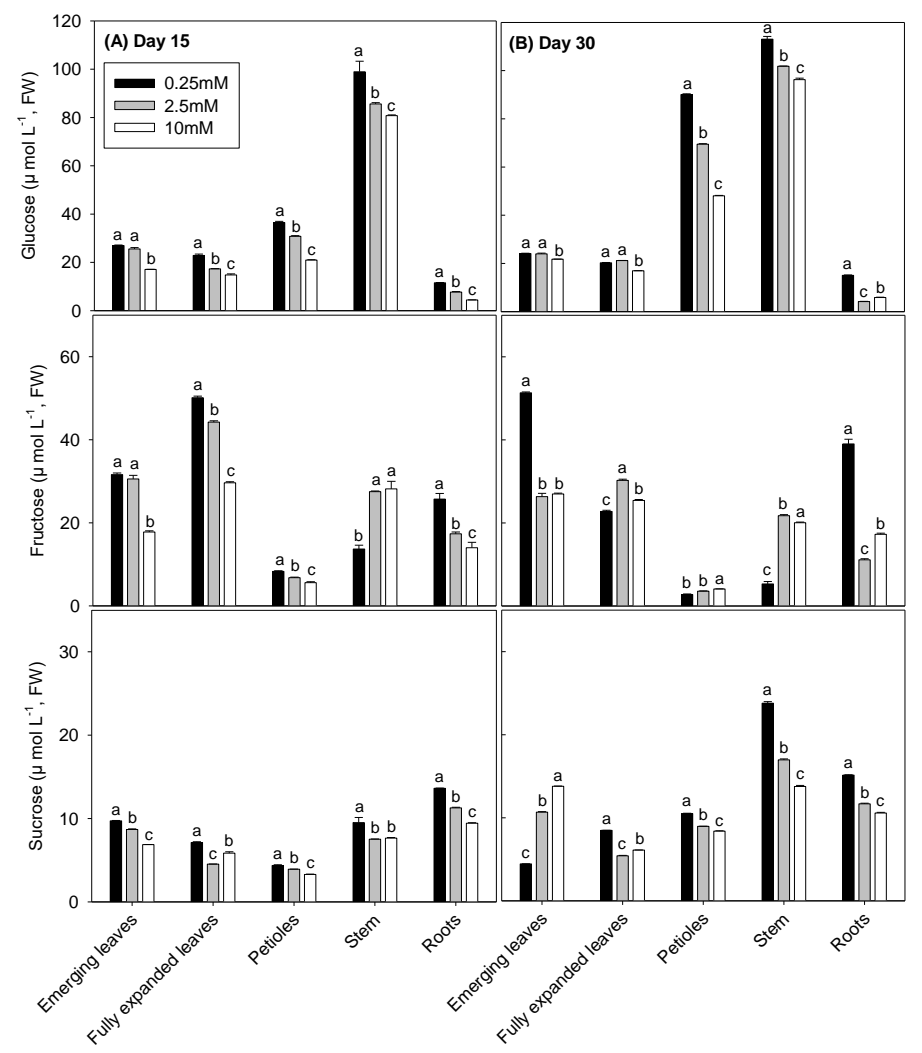

Fig 3. Temporal and tissues-dependent composition in soluble sugars, glucose, fructose and sucrose, in differently K-supplied tomato plants $(n=3)$. Tomato plants were grown in a nutrient solution with $0.25 \mathrm{mM} \mathrm{KNO}_{3}$, and $0.025 \mathrm{mM} \mathrm{KH}_{2} \mathrm{PO}_{4}$ for low $\mathrm{K}$ nutrition, and $10.0 \mathrm{mM} \mathrm{KNO}_{3}$, and $1.0 \mathrm{mM} \mathrm{KH}_{2} \mathrm{PO}_{4}$ for high $\mathrm{K}$ nutrition. Plants were harvested at the 15 and $30^{\text {th }}$ day after nutrient treatment.

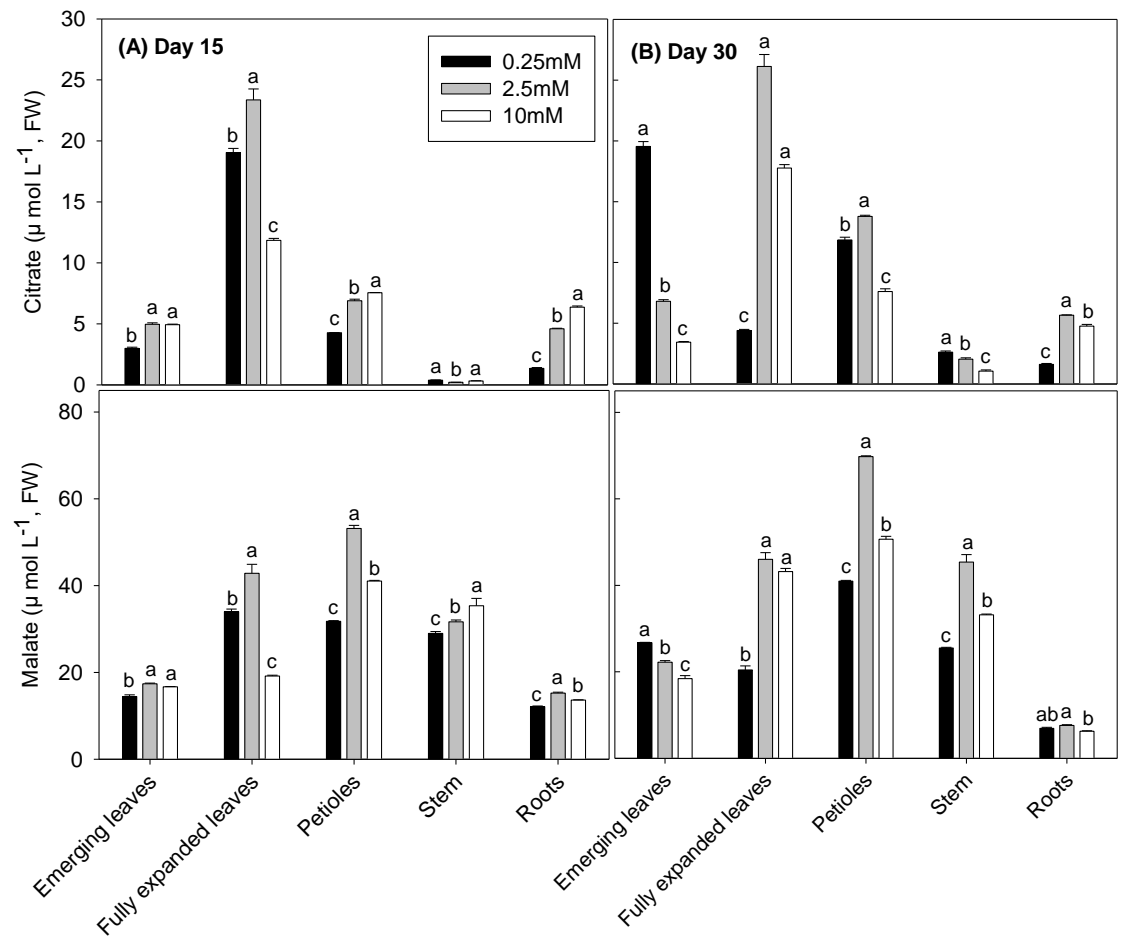

Fig 4. Temporal and tissues-dependent composition in organic acids, citrate and malate, in differently K-supplied tomato plants ( $\mathrm{n}=3$ ). Tomato plants were grown in a nutrient solution with $0.25 \mathrm{mM} \mathrm{KNO}_{3}$ and $0.025 \mathrm{mM} \mathrm{KH}_{2} \mathrm{PO}_{4}$ for low $\mathrm{K}$ nutrition, and $10.0 \mathrm{mM}$ $\mathrm{KNO}_{3}$, and $1.0 \mathrm{mM} \mathrm{KH}_{2} \mathrm{PO}_{4}$ for high $\mathrm{K}$ nutrition. Plants were harvested at the 15 and $30^{\text {th }}$ day after nutrient treatment. 


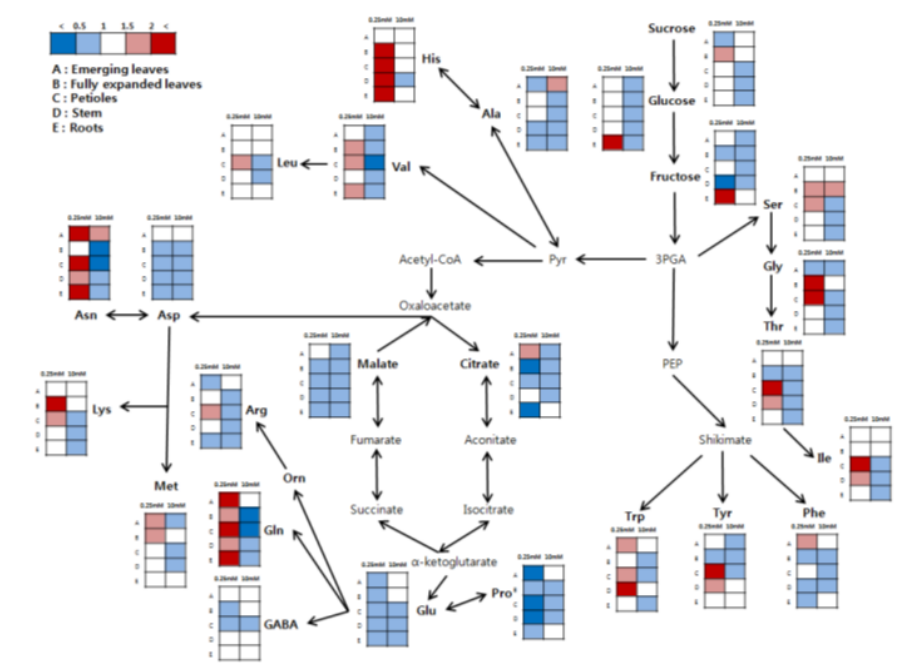

Fig 5. Mapping of measured metabolites onto the primary metabolic pathways. Ratios of changes in metabolite concentrations in tomato tissues subjected to low- $(0.25 \mathrm{mM})$ or high-K $(10 \mathrm{mM})$ nutrition status are shown as heat maps, and were calculated from an average of the results measured at 15 and 30 days after $\mathrm{K}$ treatments.

supported from the experiment (Yamada et al. 2002; Armengaud et al. 2009), which observed the limited carbon flux into the TCA cycle and amino acids under low $\mathrm{K}$, and thus led to higher ratio of glutamine/glutamate and asparagines/aspartate, which was also observed in other nutrient stresses such as N, P and S (Hirai et al. 2004; Nikiforova et al. 2004; Huang et al. 2008). In general, K particularly favors the incorporation of amino acids into proteins; however, there is insufficient information to understand $\mathrm{C} / \mathrm{N}$ metabolism (regulation of primary metabolite) in plants affected by excessive $\mathrm{K}$ nutrition ( $\mathrm{Li}$ et al. 1997). It was reported that a high level of mineral supply such as nitrogen promotes the changes in $\mathrm{C} / \mathrm{N}$ metabolism, decreased soluble sugars, whereas, increased organic and amino acids (Scheible et al. 1997, 2000; Okazaki et al. 2008). The results in this study (Fig. 5) indicated that high $\mathrm{K}$ nutrition showed a significant decrease of primary metabolites measured in all plant tissues. On the basis of these reports, it can be presumed that an excessively absorbed $\mathrm{K}$ induces higher biosynthesis and activation of proteins, resulting in marked decrease of primary metabolites, and much more storage into vacuoles to regulate cellular $\mathrm{pH}$ stabilization and ion balance; however, further efforts to elucidate possible $\mathrm{K}$-dependent events is necessary. In conclusion, many previous studies have focused on the primary metabolic changes mostly in leaves and the roots under several mineral deficiency conditions, while this study has investigated tissues-specific changes in tomato plants grown under low- or high-K nutrition conditions. The data presented here provides several new findings: 1) measured metabolites responded differently according to $\mathrm{K}$ nutrition levels that resulted in approximately $50 \%$ portion of increase or decrease under low $\mathrm{K}$ and mostly a decrease (more than $80 \%$ ) under high $\mathrm{K}$; 2) It was discovered that the petioles are the most sensitive tissue in response to K nutrition levels; 3) the most altered metabolites were glutamine, asparagine and histidine (up-regulated) and glutamate, aspartate, proline, malate and citrate (down-regulated) in low $\mathrm{K}$, and glutamine, asparagine, and valine (down-regulated) in high $\mathrm{K}$. Therefore, it is clear that more studies are required to understand and to accumulate more comprehensive information involving the spatio-temporal metabolic networks affected by a variety of mineral conditions, and due to the somewhat downstream response of metabolite level, it is also important to simultaneously understand the responses of altered genes and protein expression involved in the metabolic networks.

\section{Materials and Methods}

\section{Plant material and growth conditions}

Tomato seeds (Solanum lycopersicum L. cv. Seonmyoung) were germinated on perlite supplied with de-ionized water for 2 weeks. Twelve uniformly sized seedlings were transplanted into holes in lids of aerated $20 \mathrm{~L}$ hydroponic containers containing 1/3-strength Hoagland solution, and grown for another 2 weeks prior to initiation of treatments. Plants were grown with permanent aeration at $25 \pm 3^{\circ} \mathrm{C}$ during the day and $15 \pm 3^{\circ} \mathrm{C}$ during the night. Mid-day photosynthetic photon flux density was $800-1200 \mu \mathrm{mol} \mathrm{m} \mathrm{m}^{-2} \mathrm{~s}^{-1}$. The nutrient solution was replaced every 3 days. The composition of nutrient solution (normal $\mathrm{K}$ ) was as follows: $2.5 \mathrm{mM} \mathrm{Ca}\left(\mathrm{NO}_{3}\right)_{2} ; 2.5 \mathrm{mM} \mathrm{KNO} \mathrm{KN}_{3} ; 1 \mathrm{mM}$ $\mathrm{MgSO}_{4} ; 0.25 \mathrm{mM} \quad \mathrm{KH}_{2} \mathrm{PO}_{4} ; 0.75 \mathrm{mM}$ Fe-EDTA; $0.5 \mathrm{mM}$ $\mathrm{NH}_{4} \mathrm{NO}_{3} ; 2 \mu \mathrm{MH}_{3} \mathrm{BO}_{3} ; 0.2 \mu \mathrm{M} \mathrm{MnCl}_{2} ; 0.190 .01 \mu \mathrm{M} \mathrm{ZnSO}_{42}$; $0.01 \mu \mathrm{M} \mathrm{CuSO}_{4}$ and $0.03 \mu \mathrm{M} \mathrm{H}_{2} \mathrm{MoO}_{4}$. In order to make lowand high- $\mathrm{K}$ nutrition conditions, $\mathrm{K}$ concentration was adjusted

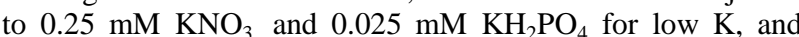
$10.0 \mathrm{mM} \mathrm{KNO}_{3}$ and $1.0 \mathrm{mM} \mathrm{KH}_{2} \mathrm{PO}_{4}$ for high $\mathrm{K}$. To minimize the effect of the altered potassium content on osmotic potential, the nutrient solution was adjusted by an equimolar mixture of ammonium nitrate and sodium phosphate to maintain the same anion concentration as that of the nutrient medium.

\section{Sample collection and preparation}

Three plants, showing similar growth in each treatment, were harvested between 10:00 and 12:00 to minimize a diurnal variation on metabolite levels at 15 and 30 days from different $\mathrm{K}$ nutrition levels (low, normal and high). The emerging leaves, fully expanded leaves, petioles, stem, and roots were briefly rinsed in de-ionized water, immediately frozen in liquid 
nitrogen, and stored at $-80^{\circ} \mathrm{C}$ until biochemical analysis. One gram of tissue was ground to a fine powder and extracted with $10 \mathrm{~mL}$ ice-cold $70 \%$ (v/v) methanol containing $0.01 \mathrm{~N} \mathrm{HCl}$. After centrifugation at $15,000 \times \mathrm{g}$ for $5 \mathrm{~min}$ to pellet cell debris, the supernatant was passed through a $0.45 \mu \mathrm{m}$ membrane filter and the filtrate was used for metabolite analysis.

\section{Metabolite analysis}

Acid-soluble amino acids were determined with an Agilent 1100 HPLC (Agilent Technologies, Wilmington, DE, USA) procedure using a pre-column derivatization method. Known volumes of each sample and 20 amino acid standards were derivatized in a total volume of $100 \mu \mathrm{L}$ using $o$-phthalaldehyde (OPA) for primary amino acids and 9-fluorenylmethyl chloroformate (FMOC) for secondary amino acids. Separations were performed on HPLC equipped with a C18 column (4.6 $\mathrm{mm} \times 150 \mathrm{~mm}, 5 \mu \mathrm{m}$ of particle size) at $40^{\circ} \mathrm{C}$. The mobile phase consisted of Eluents A (20 mM K phosphate, $\mathrm{pH} 7.8)$ and B $(\mathrm{ACN}: \mathrm{MeOH}: \operatorname{ddH} 2 \mathrm{O}=45: 45: 10, \mathrm{v} / \mathrm{v} / \mathrm{v})$. The column was preconditioned with $100 \%$ Eluent A for $10 \mathrm{~min}$. at a flow $1.5 \mathrm{~mL} \mathrm{~min}{ }^{-1}$. The injection volume for both standards and samples was $0.5 \mu \mathrm{L}$. Amino acids were eluted from the column by linearly increasing concentrations of Eluent B in the mobile phase. Eluent B was $0 \%$ between 0 and $1.9 \mathrm{~min}, 57 \%$ at $24 \mathrm{~min}$. and $100 \%$ at $26 \mathrm{~min}$. The column was then washed with $100 \%$ Eluent $\mathrm{A}$ at $4 \mathrm{~min}$. before regenerating the column. Absorbance was detected with a UV detector (Agilent G1315A) at a wavelength of $338 \mathrm{~nm}$. Quantification was based on standard curves obtained from $10 \mathrm{pmol}$ to $1 \mathrm{nmol} \mu \mathrm{l}^{-1}$ of each standard amino acid. Acid-soluble sugars were determined using an HPLC system (Dionex Ultimate 3000, USA) composed of an auto-sampler and detector (Shodex RI-101, Japan). Separation of sugars was carried out with a Waters sugar-pak (Temp. $75^{\circ} \mathrm{C}$ ) under distilled-deionized water as a mobile phase. The injection volume of each sample was $20 \mu \mathrm{L}$ and flow rate was maintained at $0.5 \mathrm{~mL} \mathrm{~min}{ }^{-1}$. Quantification was based on standard curves obtained from 50 to $10,000 \mathrm{ppm}$ of each standard of sugars. Organic acids were determined using HPLC (Agilent 1100, USA). Separations were performed for $30 \mathrm{~min}$ with an Aminex $87 \mathrm{H}$ column (Temp., $40^{\circ} \mathrm{C}$ ) under $0.01 \mathrm{~N}$ $\mathrm{H}_{2} \mathrm{SO}_{4}$ as a mobile phase. The injection volume of each sample was $20 \mu \mathrm{L}$ and flow rate was maintained $0.5 \mathrm{~mL} \mathrm{~min}^{-1}$. Absorbance was detected with a UV detector (Agilent G1315A) at a wavelength of $210 \mathrm{~nm}$. Quantification was based on

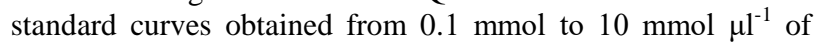
each standard of organic acid.

\section{Statistical analysis}

Statistical analysis was performed with SAS software package (version 9.1). Data were subjected to one-way ANOVA. If the ANOVA yielded a significant $\mathrm{F}$ value $(\mathrm{P}<5 \%)$, the differences among treatments were compared using a least significant difference (LSD). The data was transformed into base $2 \mathrm{log}$ scale based on the result (normal K), and the map of measured metabolites was made onto the primary metabolic pathway.

\section{Acknowledgements}

This work was carried out with the support of "Cooperative Research Program for Agriculture Science \& Technology Development (Project No. PJ010899)" Rural Development Administration, Republic of Korea.

\section{References}

Amtmann A, Troufflard S, Armengaud P (2008) The effect of potassium nutrition on pest and disease resistance in plants. Physiol Plant. 133:682-691.

Amtmann A, Blatt MR (2009) Regulation of macronutrient transport. New Phytol. 181:35-52.

Armengaud P, Sulpice R, Miller AJ, Stitt M, Amtmann A, Gibon Y (2009) Multilevel analysis of primary metabolism provides new insights into the role of potassium nutrition for glycolysis and nitrogen assimilation in Arabidopsis roots. Plant Physiol. 150:772-785.

Bednarz CW, Oosterhuis DM (1999) Physiological changes associated with potassium deficiency in cotton. J. Plant Nutr. 22:303-313.

Bölling C, Fiehn O (2005) Metabolite profiling of Chlamydomonasreinhardtii under nutrient deprivation. Plant Physiol. 139:1995-2005.

Cakmak I, Hengeler C, Marschner H (1994a) Partitioning of shoot and root dry matter and carbohydrates in bean plants suffering from phosphorus, potassium and magnesium deficiency. J Exp Bot. 45:1245-1250.

Cakmak I, Hengeler C, Marschner H (1994b) Changes in phloem export of sucrose in leaves in response to phosphorus, potassium and magnesium deficiency in bean plant. J Exp Bot. 45:1251-1257.

Farley FR, Draycott PA (1975) Growth and yield of sugar beet in relation to potassium and sodium supply. J Sci Food Agric. 26:385-392.

Hernandez G, Ramirez M, Valdes-Lopez O, Tesfaye M, Graham MA, Czechowski T, Schlereth A, Wandrey M, Erban A, Cheung F, Wu HC, Lara M, Town CD, Kopka J, Udvardi MK, Vance CP (2007) Phosphorus stress in common bean: root transcript and metabolic responses. Plant Physiol. 144:752-767.

Hirai MY, Yano M, Goodenowe DB, Kanaya S, Kimura T, Awazuhara M, Arita M, Fujiwara T, Saito K (2004) Integration of transcriptomics and metabolomics for understanding of global responses to nutritional stresses in Arabidopsis thaliana. Proc Natl Acad Sci USA. 10205-10210.

Huang CY, Roessner U, Eickmeier I, Genc Y, Callahan DL, Shirley N, Langridge P, Bacic A (2008) Metabolite profiling reveals distinct changes in carbon and nitrogen metabolism in phosphate-deficient barley plants (Hordeum vulgare L.). Plant Cell Physiol. 49:691-703.

Huber SC (1984) Biochemical basis for effects of K-deficiency on assimilate export rate and accumulation of soluble sugars in soybean leaves. Plant Physiol. 76:424-430.

Li R, Volenec JJ, Joern BC, Cunningham SM (1997) Potassium and nitrogen effects on carbohydrate and protein metabolism in alfafa roots. J Plant Nutr. 20:511-529.

Marschner H (1995) Mineral Nutrition of Higher Plants. 2nd edn. Academic Press, London.

Nikiforova VJ, Gakiere B, Kempa S, Adamik M, Willmitzer L, Hesse H, Hoefgen R (2004) Towards dissecting nutrient metabolism in plants: a systems biology case study on sulphur metabolism. J. Exp. Bot. 55:1861-1870.

Okazaki K, Oka N, Shinano T, Osaki M, Takebe M (2008) Differences in the metabolite profiles of spinach (Spinaciaoleracea L.) leaf in different concentrations of nitrate in the culture solution. Plant Cell Physiol. 49:170-177.

Pettigrew WT (1999) Potassium deficiency increases specific leaf weights and leaf glucose levels in field-grown cotton. Agron J. 91: 962-968. 
Scheible WR, Gonzalez Fontes A, Lauerer M, Muller Rober B, Caboche M, Stitt, M (1997) Nitrate acts as a signal to induce organic acid metabolism and repress starch metabolism in tobacco. Plant Cell. 9:783-798.

Scheible WR, Krap A, Stitt M (2000) Reciprocal diurnal changes of phosphoenolpyruvate carboxylase expression and cytosolic pyruvate kinase, citrate synthase and NADPisocitrate dehydrogenase expression regulate organic acid metabolism during nitrate assimilation in tobacco leaves. Plant Cell Environ. 23:1155-1167.

Sung J, Lee S, Lee Y, Ha S, Song B, Kim T, Waters BM, Krishnan HB (2015) Metabolomic profiling from leaves and roots of tomato (Solanum lycopersicum L.) plants grown under nitrogen, phosphorus or potassium-deficient condition. Plant Sci. 241:55-64.

Takahashi H, Imamura T, Miyagi A, Uchimiya H (2012) Comparative metabolomics of developmental alterations caused by mineral deficiency during in vitro culture of Gentianatriflora. Metabolomics. 8:154-163.
Urbanczyk-Wochniak E, Fernie AR (2005) Metabolic profiling reveals altered nitrogen nutrient regimes have diverse effects on the metabolism of hydroponically-grown tomato (Solanum lycopersicum) plants. J Exp Bot. 56:309-321.

Véry AA, Sentenac H (2003) Molecular mechanisms and regulation of $\mathrm{K}+$ transport in higher plants. Annu Rev Plant Biol. 54:575-603.

Wang Y, Wu WH (2010) Plant sensing and signaling in response to $\mathrm{K}^{+}$-deficiency. Mol Plant 3:280-287.

Ward GM (1960) Potassium in plant metabolism. III. Some carbohydrate changes in the wheat seedling associated with varying rates of potassium supply. Can J Plant Sci. 40:729735.

Wyn Jones RJ, Pollard A (1983) Proteins, enzymes and inorganic ions. In: Lauchli A, Pirson A (eds) Encyclopedia of Plant Physiology. Springer, Berlin, p 528-562.

Yamada S, Osaki M, Shinano T, Yamada M, Ito M, Permana AT (2002) Effect of potassium nutrition on current photosynthesized carbon distribution to carbon and nitrogen compounds among rice, soybean and sunflower. J Plant Nutr. 25:1957-1973. 